\title{
Influence of Aerobic Exercise Training on Bone Mineral Status among Chronic Obstructive Pulmonary Disease Patients
}

\author{
Shehab M Abd El Kader ${ }^{1 *}$ and Osama H Al-Jiffri ${ }^{2}$ \\ ${ }^{1}$ Department of Physical therapy, King Abdulaziz University, Saudi Arabia \\ ${ }^{2}$ Department of Medical Laboratory Technology, King Abdulaziz University, Saudi Arabia
}

Submission: February 16, 2017; Published: July 14, 2017

*Corresponding author: Prof. Shehab M. Abd El- Kader, Faculty of Applied Medical Sciences, Department of Physical Therapy, King Abdulaziz University, P.0. Box 80324, Jeddah, 21589, Saudi Arabia, Email: profshehab@live.com

Abstract

Background: Chronic obstructive pulmonary disease (COPD) characterized with abnormal bone mineral status with high risk for fracture and poor pulmonary function. Aerobic exercise was proved to improve bone mineral density (BMD) and bone geometry.

Objective: The aim of this study was to measure the impact of aerobic exercise on bone mineral status among COPD patients. Methods: Eighty patients with COPD involved in this study who were enrolled in two equal groups: group (A) received 3 sessions of treadmill aerobic exercise training every week for 6 months, while group (B) was considered as a control group who received no training intervention.

Results: The mean values of bone marrow density (BMD) of the femoral neck, lumbar spine \& total hip were improved significantly in group (A) at the end of the study, but group (B) had non-significant changes. However, the differences between mean value of the investigated parameters in both groups were significant at the end of the study $(\mathrm{p}<0.05)$.

Conclusion: Aerobic exercise is an effective treatment policy to improve bone mineral status in chronic obstructive pulmonary disease patients.

Keywords: Aerobic exercise training; Bone mineral density; Chronic obstructive pulmonary disease

Abbreviations: COPD: Chronic Obstructive Pulmonary Disease; BMD: Bone Marrow Density; EDTA: Ethylene Diamine Tetra Acetic acid; PTH Parathyroid Hormone

\section{Introduction}

Chronic Obstructive Pulmonary Disease (COPD) is an incomplete reversible progressive disorder due to its pathological manifestations [1-3] one of the extra-pulmonary manifestations is skeletal muscle dysfunction which affects patients with COPD more than health subjects by two to five folds [4-6], the decline in bone mineral density (BMD) was found to be correlated with the decline in the lung functions [7]. Moreover, about 6-70\% of COPD patients affected with osteoporosis according to the severity of illness [8]. The strength of the handgrip strength was found to be closely related to body lean mass, percentage of fat, fat mass composition and BMD [9].

Globally, COPD is a prevalent disorder [10] with high risk of osteoporosis along with high economic burden of the disease medical care [8-12]. COPD is the third cause of death in
America [13]. By 2030 it is expected to have 9 million subject die from COPD every year $[14,15]$. Currently COPD is the 5 th leading cause of death and 3rd economic burden of disease care $[16,17]$.

About 10\% drug-related complications and 141,000 of USA hospital stays were related to corticosteroids in 2004 [18]. In addition, corticosteroids-induced osteoporosis via bone formation suppression and enhanced bone resorption [19] which is usually associated with intake of moderate or high doses of inhaled corticosteroids (ICS) [20]. Long-term low-dose ICS use increases the rate of bone marrow density (BMD) loss in patients with chronic obstructive pulmonary disease [21-23].

The regular pharmacological agents for osteoporosis have high cost and unlimited side-effects specially with long term intake which limit their use $[24,25]$, these side-effects of the 
pharmacological therapy forced the medical care members to the non-pharmacological treatment for COPD [26]. Weight bearing exercises of moderate to high intensity have a good role in maintenance of bone mineral status among adult populations [27], therefore exercise training is widely accepted treatment strategy for osteoporosis prevention [28]. The purpose of this study was to measure the impact of aerobic exercise on BMD among COPD patients.

\section{Materials and methods}

\section{Subjects}

Eighty patients with moderate severity of COPD according to GOLD [29] were enrolled in this study. Patients with exacerbations in the last 4 weeks were either rescheduled or excluded; their age ranged from 36 to 57 years. Exclusion criteria included smokers, hepatic disorders, cardiac disorders, renal disorders, diabetes, musculoskeletal disorders. Participants were enrolled in two equal groups, the first group (A) received their traditional treatment in addition to treadmill aerobic exercises, while the second group (B) was considered as a control group and received only their traditional treatment for six months. The CONSORT diagram clearly outline the screening details and phases of randomization phases (Figure 1). Informed consent was signed by all participants. This study was approved by the Scientific Research Ethical Committee, Faculty of Applied Medical Sciences at King University.

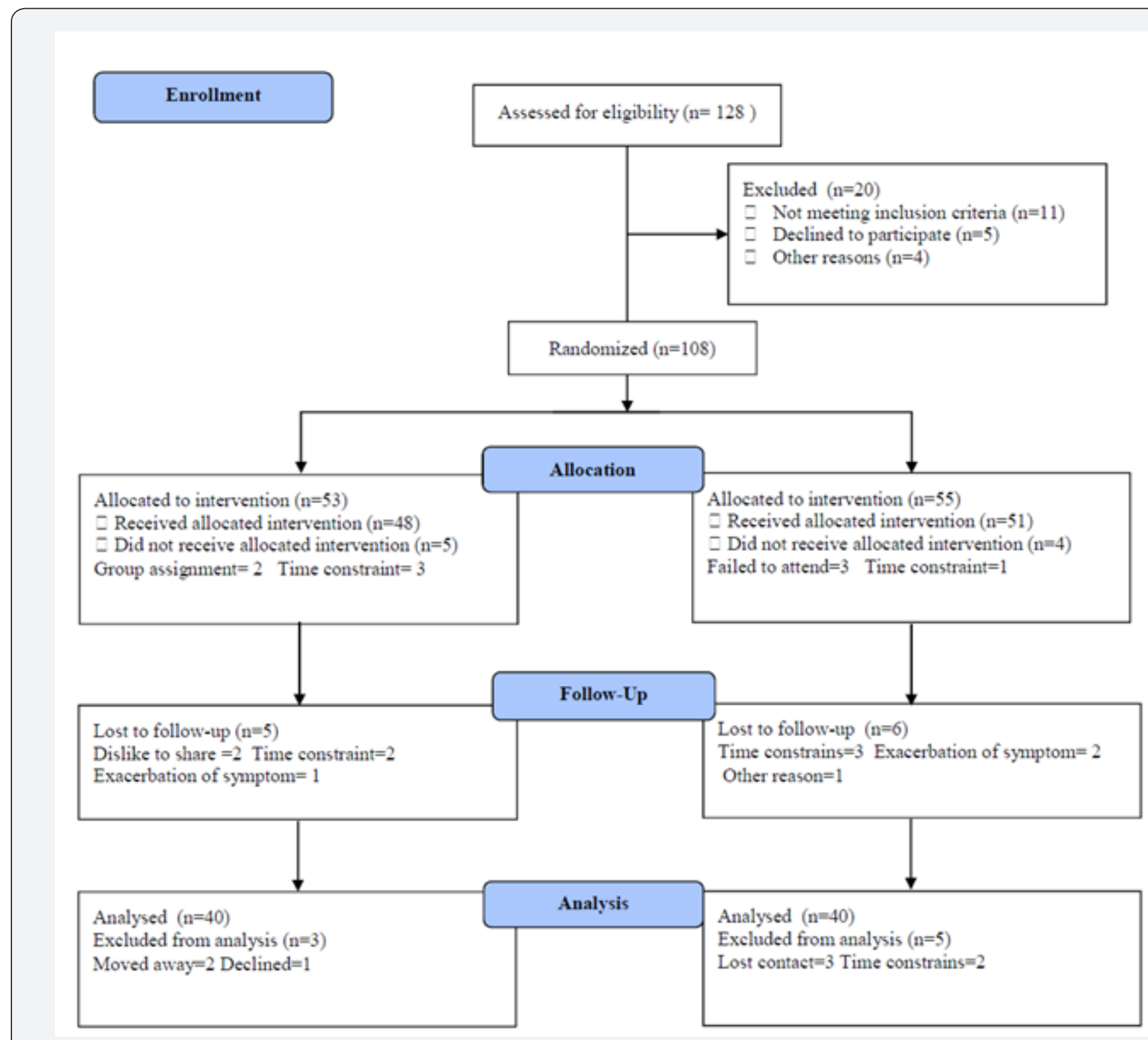

Figure 1: Subjects screening and recruitment CONSORT diagram. 


\section{Measurements}

Overnight fasting venous blood samples were added to Ethylene diamine tetra acetic acid (EDTA), and centrifuged for $10 \mathrm{~min}$ at $1000 \times \mathrm{g}$. Samples stored at $-80^{\circ} \mathrm{C}$ until analysis. Parathyroid hormone (PTH) and serum blood calcium were measured with an Enzyme Linked Immuno Sorbent Assay (ELISA) (Diagnostics Systems Laboratories, Inc., Webster, TX). However, measurements of BMD of total hip, lumbar spine and the femoral neck were taken by Dual Energy X-Ray Absorptiometry ((DXA) GE Lunar Prodigy enCORE software version 8.80, GE Medical Systems, Madison WI).

\section{Procedures}

Participants were randomly included into two equal groups as following:

a. Group (A) received treadmill aerobic exercise training with a five minutes warming-up phase done on the treadmill (Track master 400E, gas fitness system, England) with low load, actual training time was thirty minutes with an intensity of $70-80 \%$ of HRmax and finally five minutes of cooling down that was done in the form of running or walking [30].

b. Group (B) was considered as a control group and received no training intervention for six months.

\section{Statistical analysis}

SPSS (Chicago, IL, USA) version 17 was used in statistical analysis, where the investigated parameters of both groups obtained before and at the end of the study were compared. However, comparison between the investigated parameters of both groups done using independent " $t$ ". All data were expressed as the mean $\pm \mathrm{SD}(\mathrm{P}<0.05)$.

Table 1: Participants baseline characteristics in both groups.

\begin{tabular}{|c|c|c|c|}
\hline \multirow{2}{*}{} & \multicolumn{2}{|c|}{ Mean \pm SD } & P value \\
\cline { 2 - 4 } & Group (A) & Group (B) & 0.564 \\
\hline Age (year) & $48.37 \pm 4.62$ & $46.91 \pm 4.58$ & 0.371 \\
\hline Gender ratio (male/female) & $26 / 14$ & $25 / 15$ & 0.253 \\
\hline BMI (kg/m²) & $22.16 \pm 3.49$ & $21.42 \pm 3.51$ & 0.218 \\
\hline FVC (L) & $2.81 \pm 0.78$ & $2.95 \pm 0.84$ & 0.063 \\
\hline FEV1 (L) & $1.62 \pm 0.67$ & $1.44 \pm 0.63$ & 0.127 \\
\hline FEV1/FVC (\%) & $48.65 \pm 6.24$ & $50.13 \pm 7.11$ & 0.352 \\
\hline MVV (L/minute) & $51.28 \pm 8.16$ & $53.42 \pm 9.38$ & \\
\hline
\end{tabular}

BMI: Body Mass Index; FVC: Forced Vital Capacity; FEV1: Forced Expiratory volume in the First Second; FEV1/FVC: Ratio between Forced Expiratory Volume in the First Second and Forced Vital Capacity; MVV: Maximum Voluntary Ventilation.

\section{Results}

The baseline characteristics of all participants are shown in Table 1 . Most participants (65\%) were men. Forty participants were assigned to the aerobic exercise group $(n=40 ; 26$ males and 14 females), while the resistance exercise group ( $\mathrm{n}=40$; 25 males and 15 females). None of the baseline characteristics differed significantly between the two groups is listed in Table 1.

The mean values of bone marrow density (BMD) of

Table 2: Mean value and significance of the investigated parameters in group (A) before and at the end of the study.

\begin{tabular}{|c|c|c|c|c|}
\hline \multirow{2}{*}{} & \multicolumn{2}{|c|}{ Mean \pm SD } & \multirow{2}{*}{ T-value } & P value \\
\cline { 2 - 4 } & $7.86 \pm 2.13$ & After & 7.74 & $0.007^{*}$ \\
\hline Serum Calcium (ng/dl) & $13.95 \pm 3.12$ & $10.33 \pm 2.74^{*}$ & 7.31 & $0.002^{*}$ \\
\hline $\begin{array}{c}\text { Parathyroid Hormone } \\
\text { (ng/dl) }\end{array}$ & $0.916 \pm 0.128$ & $1.23 \pm 0.141^{*}$ & 6.412 & $0.015^{*}$ \\
\hline Total hip BMD (g/cm ${ }^{2}$ ) & $1.087 \pm 0.232$ & $1.294 \pm 0.246^{*}$ & 8.351 & $0.009^{*}$ \\
\hline $\begin{array}{c}\text { Lumbar spine BMD (g/ } \\
\text { cm }^{2} \text { ) }\end{array}$ & $0.794 \pm 0.176$ & $0.973 \pm 0.181^{*}$ & 8.52 & $0.011^{*}$ \\
\hline $\begin{array}{c}\text { Femoral neck BMD (g/ } \\
\mathrm{cm}^{2} \text { ) }\end{array}$ & $145.64+10.71$ & $176.85+9.63^{*}$ & 8.52 & $0.006^{*}$ \\
\hline $\begin{array}{c}\text { Hand grip strength } \\
\text { (mmHg) }\end{array}$ & & & \\
\hline
\end{tabular}

BMD: Bone Marrow Density; ( $\left.{ }^{*}\right)$ indicates a significant difference between the two groups, $\mathrm{P}<0.05$. 


\section{International Journal of Pulmonary \& Respiratory Sciences}

Table 3: Mean value and significance of the investigated parameters in group (B) before and at the end of the study.

\begin{tabular}{|c|c|c|c|c|}
\hline \multirow{2}{*}{} & \multicolumn{2}{|c|}{ Mean \pm SD } & \multirow{2}{*}{ T-value } & P value \\
\cline { 2 - 4 } & $7.57 \pm 1.64$ & After & 0.81 & 0.315 \\
\hline Serum Calcium (ng/dl) & $13.78 \pm 3.22$ & $13.94 \pm 3.31$ & 0.92 & 0.472 \\
\hline $\begin{array}{c}\text { Parathyroid Hormone } \\
\text { (ng/dl) }\end{array}$ & $0.923 \pm 0.131$ & $0.918 \pm 0.130$ & 0.987 & 0.168 \\
\hline Total hip BMD (g/cm ${ }^{2}$ ) & $1.117 \pm 0.217$ & $1.094 \pm 0.213$ & 0.843 & 0.516 \\
\hline $\begin{array}{c}\text { Lumbar spine BMD (g/ } \\
\text { cm }^{2} \text { ) }\end{array}$ & $0.821 \pm 0.183$ & $0.765 \pm 0.174$ & 0.756 & 0.317 \\
\hline $\begin{array}{c}\text { Femoral neck BMD (g/ } \\
\mathrm{cm}^{2} \text { ) }\end{array}$ & $146.24+10.92$ & $142.15+10.36$ & 1.37 & 0.165 \\
\hline $\begin{array}{c}\text { Hand grip strength } \\
\text { (mmHg) }\end{array}$ & & & \\
\hline
\end{tabular}

BMD: Bone Marrow Density

Table 4: Mean value and significance of the investigated parameters in group (A) and group (B) at the end of the study.

\begin{tabular}{|c|c|c|c|c|}
\hline & \multicolumn{2}{|c|}{ Mean \pm SD } & \multirow{2}{*}{ T-value } & \multirow{2}{*}{$P$ value } \\
\hline & Group (A) & Group (B) & & \\
\hline Serum Calcium (ng/dl) & $9.87 \pm 2.51^{*}$ & $7.39 \pm 1.22$ & 5.41 & $0.025^{*}$ \\
\hline $\begin{array}{l}\text { Parathyroid Hormone } \\
\text { (ng/dl) }\end{array}$ & $10.33 \pm 2.74^{*}$ & $13.94 \pm 3.31$ & 5.73 & $0.017^{*}$ \\
\hline Total hip BMD $\left(\mathrm{g} / \mathrm{cm}^{2}\right)$ & $1.23 \pm 0.141^{*}$ & $0.918 \pm 0.130$ & 6.115 & $0.013^{*}$ \\
\hline $\begin{array}{l}\text { Lumbar spine BMD (g/ } \\
\left.\qquad \mathrm{cm}^{2}\right)\end{array}$ & $1.294 \pm 0.246^{*}$ & $1.094 \pm 0.213$ & 8.351 & $0.005^{*}$ \\
\hline $\begin{array}{l}\text { Femoral neck BMD }(\mathrm{g} / \\
\left.\mathrm{cm}^{2}\right)\end{array}$ & $0.973 \pm 0.181^{*}$ & $0.765 \pm 0.174$ & 8.52 & $0.007^{*}$ \\
\hline $\begin{array}{l}\text { Hand grip strength } \\
(\mathrm{mmHg})\end{array}$ & $176.85+9.63^{*}$ & $142.15+10.36$ & 6.82 & $0.016^{*}$ \\
\hline
\end{tabular}

BMD: Bone Marrow Density; $\left({ }^{*}\right)$ indicates a significant difference between the two groups, $\mathrm{P}<0.05$.

\section{Discussion}

The American College of Sports Medicine (ACSM) recommended regular weight-bearing to preserve bone mass [31]. However, Greendale and colleagues stated that exercise can prevent osteoporosis [32]. Therefore, this study was designed to measure the impact of aerobic exercise on bone mineral status among COPD patients. The main finding of our study indicated that aerobic exercise training improves bone mineral status among patients with COPD. These findings approved by Lester et al. [33] stated that only long term exercise training for a period more than 6 months was enough to improve bone mineral density [33]. Also, Nordstrom et al. [34] reported that BMD improved among athletes who participate in weightbearing activities [34]. While Bonaiuti [35] and colleague's recommended walking exercise for prevention and treatment of osteoporosis in postmenopausal women [35]. However, Hind et al. [36] reported that BMD improve in cystic fibrosis children after 6 months of regular weight-bearing exercise [36]. While, Remes et al. [37] said that exercise is essential for middle-aged men to have peak bone mass [37]. Also, Lin et al. stated that weight-bearing exercise had a greater positive effect on BMD than the non-weight-bearing exercise [38]. Moreover, Douchi et al. [39] confirmed that strength training significantly increased BMD of lumbar spine in postmenopausal women [39].

The possible mechanism by which exercise maintains the skeletal integrity are: changes in the biochemical structure of the blood by altering the level of its component which has a role in the integrity of normal skeletal and mechanical load of the exercise which can modify and increase bone mass [40]. The increase in bone mineral density after exercise may be due to increase in serum calcium associated with decreased parathyroid hormone following exercise training [41].

The present study has important limitations and strengths. The supervised nature of the study is a point of strength as it limit the need to rely on activity questionnaires or to have a dubiety regarding compliance and adherence of participants in training. Moreover, the study was randomized; hence, we can ensure adherence to the general population. While, the possibility of findings generalization may be limited by the small sample size in both groups. Finally, based on the present study findings, treadmill walking exercise training is an effective 
treatment policy to modulate bone mineral status in COPD patients. Further researches are needed to explore the impact of exercise training upon quality of life and other biochemical parameters among COPD patients.

\section{Conclusion}

Aerobic exercise is an effective treatment policy to improve BMD in patients with COPD.

\section{Acknowledgment}

This project was funded by the Deanship of Scientific Research (DSR) at King Abdulaziz University, Jeddah, under grant no. (G-56-142-34). The authors, therefore, acknowledge with thanks DSR for technical and financial support.

\section{References}

1. Rabe K, Hurd S, Anzueto A (2007) Global strategy for the diagnosis, management, and prevention of chronic obstructive pulmonary disease: GOLD executive summary. Am J Respir Crit Care Med 176(6): 532-555.

2. Spruit M, Pennings H, Janssen P, Does JD, Scroyen S, et al. (2007) Extrapulmonary features in COPD patients entering rehabilitation after stratification for MRC dyspnea grade. Respir Med 101(12): 2454-2463.

3. Spruit M, Watkins M, Edwards L, Vestbo J, Calverley PM, et al. (2010) Determinants of poor 6-min walking distance in patients with COPD: the ECLIPSE cohort. Respir Med 104(6): 849-857.

4. Kjensli A, Falch J, Ryg M, Blenk T, Armbrecht G, et al. (2009) High prevalence of vertebral deformities in COPD patients: relation to disease severity. Eur Respir J 33(5): 1018-1024.

5. Maggi S, Siviero P, Gonnelli S, Schiraldi C, Malavolta N, et al. (2009) Osteoporosis Risk in Patients with Chronic Obstructive Pulmonary Disease: The EOLO Study. J Clin Densitom 12(3): 345-352.

6. Sabit R, Bolton C, Edwards P, Pettit RJ, Evans WD, et al. (2007) Arterial stiffness and osteoporosis in chronic obstructive pulmonary disease. Am J Respir Crit Care Med 175(12): 1259-1265.

7. Fountoulis G, Minas M, Georgoulias P, Fezoulidis I, Gourgoulianis K, et al. (2012) Association of Bone Mineral Density, Parameters of Bone Turnover, and Body Composition in Patients with Chronic Obstructive Pulmonary Disease. Journal of Clinical Densitometry 15(2): 217-223.

8. Graat-Verboom L, Spruit M, van den Borne B, Smeenk F, Martens E, et al. (2009) Correlates of osteoporosis in chronic obstructive pulmonary disease: An underestimated systemic component. Respir Med 103(8): 1143-1151.

9. Marin R, Pedrosa M, Moreira-Pfrimer L, Matsudo S, Lazaretti-Castro M (2010) Association between Lean Mass and Handgrip Strength with Bone Mineral Density in Physically Active Postmenopausal Women. J Clin Densitom 13(1): 96-101.

10. Pobeha P, Ukropec J, Skyba P, Ukropcova B, Joppa P, et al. (2011) Relationship between osteoporosis and adipose tissue leptin and osteoprotegerin in patients with chronic obstructive pulmonary disease. Bone 48(5): 1008-1014.

11. Fountoulis G, Minas M, Georgoulias P, Fezoulidis I, Gourgoulianis K, et al. (2011) Association of adipokines, markers of bone metabolism, bone mineral density and body composition in men with chronic obstructive pulmonary disease. Bone 48(Suppl 2): S190.

12. Graat-Verboom L, Smeenk F, van den Borne B, Spruit M, Donkers-van
Rossum A, et al. (2012) Risk factors for osteoporosis in Caucasian patients with moderate chronic obstructive pulmonary disease: A case control study. Bone 50(6): 1234-1239.

13. NHLBI morbidity and Mortality Chartbook.

14. Mathers C, Loncar D (2006) Projections of global mortality and burden of disease from 2002 to 2030. PLoS Med 3(11): e442.

15. Rosenberg S, Kalhan R (2012) Biomarkers in chronic obstructive pulmonary disease Translational Research 159(4): 228-237.

16. Australian Institute of Health and Welfare. COPD (chronic obstructive pulmonary disease).

17. Global Strategy for the diagnosis, management and prevention of chronic obstructive pulmonary disease. Global Initiative for Chronic Obstructive Lung Disease.

18. Elixhauser A, Owens P (2007) Adverse drug events in U.S. hospitals, 2004. Healthcare Cost and Utilization Project. Statistical Brief \#29.

19. Dore RK (2010) How to prevent glucocorticoid-induced osteoporosis. Cleve Clin J Med 77(8): 529-536.

20. Avenell A, Gillespie WJ, Gillespie LD (2009) Vitamin D and vitamin D analogues for preventing fractures associated with involutional and post-menopausal osteoporosis. Cochrane Database Syst Rev 20(3): CD000227.

21. Mathioudakis AG1, Amanetopoulou SG, Gialmanidis IP, ChatzimavridouGrigoriadou V, Siasos G, et al. (2013) Impact of long-term treatment with low-dose inhaled corticosteroids on the bone mineral density of chronic obstructive pulmonary disease patients: aggravating or beneficial? Respirology 18(1): 147-153.

22. Chee C, Sellahewa L, Pappachan JM (2014) Inhaled corticosteroids and bone health. Open Respir Med J 8: 85-92.

23. Stoloff SW, Kelly HW (2011) Updates on the use of inhaled corticosteroids in asthma. Curr Opin Allergy Clin Immunol 11(4): 337344 .

24. Rossouw J, Anderson G, Prentice R, LaCroix A, Kooperberg C, et al. (2002) Risks and benefits of estrogen plus progestin in healthy postmenopausal women: principal results from the Women's Health Initiative randomized controlled trial. JAMA 288(3): 321-333.

25. Weycker D, Macarios D, Edelsberg J, Oster G (2006) Compliance with drug therapy for postmenopausal osteoporosis. Osteoporos Int 17(11): 1645-1652.

26. Hamilton C, Thomas S, Jamal S (2010) Associations between leisure physical activity participation and cortical bone mass and geometry at the radius and tibia in a Canadian cohort of postmenopausal women. Bone 46(3): 774-779.

27. Kohrt W, Bloomfield S, Little K, Nelson M, Yingling V (2004) American College of Sports Medicine position stand on physical activity and bone health. Med Sci Sports Exer 36(11): 1985-1996.

28. Lane N (2006) Epidemiology, etiology, and diagnosis of osteoporosis. Am J Obstet Gynecol 194(2 Suppl): S3-S11.

29. GOLD Scientific Committee. Global strategy for the diagnosis, management and prevention of chronic obstructive pulmonary disease. GOLD Scientific Committee.

30. Robergs R, Landwehr R (2002) The surprising history of the "HRmax=220-age" equation. J Exerc Physiol Online 5(2): 1-10.

31. Kohrt W, Bloomfield S, Little K, Nelson M, Yingling V, et al. (2004) American College of Sports Medicine Position Stand: physical activity and bone health. Med Sci Sports Exerc 36(11): 1985-1996. 
32. Greendale G, Huang M, Wang Y, Finkelstein J, Danielson M, Sternfeld B (2003) Sport and home physical activity are independently associated with bone density. Med Sci Sports Exerc 35(3): 506-512.

33. Lester M, Urso M, Evans R, Pierce J, Spiering B, et al. (2009) Influence of exercise mode and osteogenic index on bone biomarker responses during short-term physical training. Bone 45(4): 768-776.

34. Nordström A, Olsson T, Nordström P (2006) Sustained benefits from previous physical activity on bone mineral density in males. J Clin Endocrinol Metab 91(7): 2600-2604.

35. Bonaiuti D, Shea B, Iovine R, Negrini S, Robinson V, et al. (2002) Exercise for preventing and treating osteoporosis in postmenopausal women (review). Cochrane Database Syst Rev 3: CD000333.

36. Hind K, Truscott J, Conway S (2008) Exercise during childhood and adolescence: A prophylaxis against cystic fibrosis-related low bone mineral density? Exercise for bone health in children with cystic fibrosis. J Cyst Fibrosis 7(4): 270-276.
37. Remes T, Väisänen SB, Mahonen A, Huuskonen J, Kröger H, et al. (2004) The association of bone metabolism with bone mineral density, serum sex hormone concentrations, and regular exercise in middle-aged men. Bone 35(2): 439-447.

38. Lin L, Lo M, Yao W, Hung C (2005) The effects of different weight-bearing exercise training on bone mineral density and bone metabolism in young men. Journal of Science and Medicine in Sport; 12(Supplement 2): e123-e124.

39. Douchi T, Yamamoto S, Oki T, Maruta K, Kuwahata R, et al. (2000) The effects of physical exercise on body fat distribution and bone mineral density in postmenopausal women. Maturitas 35(1): 25-30.

40. Ljunghall S, Joborn H, Benson L, Fellström B, Wide L, Akerstrom G (1984) Effects of physical exercise on serum calcium and parathyroid hormone. Eur J Clin Invest 14(6): 469-473.

41. Grimston S, Tanguay K, Gundberg C, Hanley D (1993) The caliotropic hormone response to changes in serum calcium during exercise in female J Clin Endocrinol Metab 76(4): 867-872.

This work is licensed under Creative Commons Attribution 4.0 Licens DOI: 10.19080/IJOPRS.2017.02.555577 